\title{
1 Synchrotron X-ray Fluorescence Imaging Evidence of Biogenic Mercury Identified in a
}

\section{Burial in Colonial Antigua}

4 Treena Swanston ${ }^{1, *}$, Tamara Varney ${ }^{2}$, Ian Coulthard ${ }^{3}$, Graham N. George ${ }^{4}$, Ingrid J. Pickering ${ }^{4}$, $5 \quad$ Reg Murphy ${ }^{5}$, and David M.L. Cooper ${ }^{6}$

6

7 1, ${ }^{*}$ Department of Archaeology and Anthropology, University of Saskatchewan, Saskatoon, SK,

8 S7N 5B1, Canada, (W)306-966-4177, (F)306-966-5640, treena.swanston@ usask.ca;

$9 \quad{ }^{2}$ Department of Anthropology, Lakehead University, Thunder Bay, ON, P7B 5E1, Canada;

$10{ }^{3}$ Canadian Light Source, Saskatoon, SK, S7N 0X4, Canada; ${ }^{4}$ Department of Geological Sciences,

11 University of Saskatchewan, Saskatoon, SK, S7N 5E2, Canada; ${ }^{5}$ National Parks Antigua, West

12 Indies; ${ }^{6}$ Department of Anatomy and Cell Biology, University of Saskatchewan, Saskatoon, SK,

13 S7N 5E5, Canada

14

15

16

17

18 Keywords: synchrotron; bone; trace elements

19 
22 A mass spectroscopic analysis of bone samples from 17 individuals once buried in a Royal Naval

23 Hospital cemetery (1793-1822) in Antigua revealed a high level of mercury (Hg) in one

24 individual. While the toxic properties of $\mathrm{Hg}$ are now recognized, this metal was used for

25 centuries to treat ailments such as syphilis and yellow fever. Synchrotron radiation X-ray

26 fluorescence imaging (XFI) was employed to determine whether the $\mathrm{Hg}$ was present in the bone

27 as a result of environmental contamination or due to biogenic uptake. The XFI study revealed

28 that only a localized subset of the osteons within a $2.5 \mathrm{~mm}$ by $1.5 \mathrm{~mm}$ scan contained $\mathrm{Hg}-\mathrm{a}$

29 finding consistent with biogenic uptake. The near-edge portion of the X-ray absorption spectrum

30 was used to determine that the $\mathrm{Hg}$ was present in the bone tissue as an inorganic mercuric

31 sulfide. 


\section{Introduction}

Mercury $(\mathrm{Hg})$ has been recognized as an element of human interest for millennia

34 (Aufderheide and Rodriguez-Martin, 1998). The first evidence of $\mathrm{Hg}$ in the archaeological

35 record was identified in $18^{\text {th }}$ dynasty Egyptian tombs circa 3500 years BP (Abramowitz, 1934).

36 This element has been used for decoration (Yamada, et al., 1995, Yamada, et al., 1997) and as a

37 component in medicine, especially in recent centuries when it was used to treat syphilis (Lopes,

38 et al., 2010, Tucker, 2007, Kepa, et al., 2012). As part of a larger study of identifying the

39 biogenic uptake of trace elements in archaeological bone through the use of synchrotron

40 techniques (Swanston, et al., 2012), inductively coupled plasma mass spectrometry (ICP-MS)

41 was used to determine the concentrations of trace elements in 17 bone samples from individuals

42 recovered from a colonial Royal Naval Hospital Cemetery (1793-1822). This cemetery, which is

43 located in Antigua, West Indies, was partially excavated due to modern construction. Our

44 primary research goals included using ICP-MS to identify bone samples with high lead

45 concentrations; however, this analysis revealed that a sample from one individual contained a

46 high concentration of $\mathrm{Hg}$.

$47 \quad \mathrm{Hg}$ is a heavy metal that exists in three broad chemical species: elemental $\mathrm{Hg}$, inorganic

$48 \mathrm{Hg}$, and organic $\mathrm{Hg}$ (Guzzi and La Porta, 2008), all of which show some level of toxicity. Hg can

49 be identified using standard X-ray fluorescence instrumentation (Toribara and Jackson, 1982) but

50 it is difficult to determine whether the element was introduced in the burial environment or

51 associated with a biological event during life. In the $17^{\text {th }}$ century, topical mercuric treatments for

52 syphilis became popular and calomel (inorganic mercurous chloride) was used as a purgative in

53 medicine. By the late $18^{\text {th }}$ century, it was common to take elemental Hg orally (Sartin and Perry,

54 1995). Interestingly, five years after the final burial at the Antigua Royal Naval Hospital 
cemetery (1793-1822), Dr. Anthony Musgrave, the Surgeon-General on the Colonial Staff of

56 Antigua, wrote an article on the use of $\mathrm{Hg}$ in the early $19^{\text {th }}$ century (Musgrave, 1827). He

57 described how patients were treated with a course of quicksilver pills (elemental Hg) when they

58 had symptoms of syphilis or yellow fever.

As a way of testing the hypothesis that $\mathrm{Hg}$ was deposited in the bone sample from the

60 Royal Naval Cemetery in Antigua via biogenic uptake rather than post-mortem diagenetic

61 modification we employed synchrotron radiation X-ray fluorescence imaging (XFI) to examine

62 the spatial distribution of the element and X-ray absorption spectroscopy (XAS) to obtain

63 chemical speciation information. Specifically, we sought to determine 1) if the spatial elemental

64 distribution was correlated with microstructural features in the bone and 2) if the nature of the

65 chemical species was consistent with biogenic deposition.

\section{2. Material and Methods}

The colonial Royal Naval Hospital cemetery (1793-1822) in English Harbour, Antigua

69 was excavated between the years of 1998 and 2001, and bone samples are currently curated in

70 co-author Varney’s laboratory at Lakehead University, Thunder Bay, Canada. Ethics approval

71 was obtained from the University of Saskatchewan Biomedical Research Ethics Board. Prior to

72 this Hg study, ICP-MS was completed to identify bulk element concentrations using standard

73 methodologies at the ICP-MS Laboratory in the Department of Geological Sciences, University

74 of Saskatchewan (Jenner, et al., 1990, Stefanova, et al., 2003).

75 The bone sample of interest had a $\mathrm{Hg}$ level of $94.6 \mathrm{ppm}$ in comparison to the other

76 sixteen samples that ranged between 0 and $2 \mathrm{ppm}$. The sample was a tibial cortical fragment that

77 belonged to a male individual who was approximately 25 to 29 years of age at death and was 
78 likely of European ancestry based on the cranial features present. A second sample from the

79 same tibia was tested with similar results. A gross osteological analysis of the complete set of

80 remains identified a healed fracture on the right fourth metacarpal and Schmorl's nodes on

81 thoracic vertebrae eight through twelve. In addition, the maxillary and mandibular alveolar

82 sockets were noted to be abnormally porous.

\subsection{Histological Analysis}

Bone samples were sectioned with a Buehler® IsoMet ${ }^{\circledR}$ Low Speed Saw with a diamond

86 wheel (Norton Company, TX). A $300 \mu \mathrm{m}$ bone fragment was ground to a thickness of

87 approximately $150 \mu \mathrm{m}$ with 2000 Grit 3M sandpaper. Residual material was removed by soaking

88 the bone sample for $10 \mathrm{~min}$ in an ultrasonicator. The sample was placed between Thermanox ${ }^{\circledR}$

89 metal-free plastic coverslips (Cedarlane, Burlington, ON) and examined by light microscopy.

90 The digital histological image was created using a PAXcam® high-resolution digital microscope

91 camera (PAXcam, Villa, IL) at 10x magnification.

92

\section{$93 \quad 2.2$ Synchrotron Radiation X-ray Fluorescence Imaging}

94 A two dimensional spatial map of $\mathrm{Hg}$ associated with the bone sample was initially

95 generated using XFI on the VESPERS (Very powerful Elemental and Structural Probe

96 Employing Radiation from a Synchrotron) hard X-ray microprobe bending magnet beamline

97 located at the third generation Canadian Light Source (CLS) in Saskatoon, Saskatchewan,

98 Canada (Feng, et al., 2007). The incident X-ray energy was set to $15 \mathrm{keV}$ (flux of approximately

$992 \times 10^{11}$ photons/sec) and the double multilayer monochromator had a bandwidth of $1.6 \%$.

100 Micro-focussing of the incident X-rays was achieved by using Kirkpatrick-Baez (KB) mirrors 
101 and the resulting beam spot size was approximately $5 \mu \mathrm{m}$ in diameter. Data were collected by

102 rastering the sample in steps of $10 \mu \mathrm{m}$ in length while capturing the signals from the $\mathrm{Hg} \operatorname{L} \alpha_{1,2}$

103 (9980 eV) and Hg L $\beta_{1}(11822 \mathrm{eV})$ lines. A Vortex® Silicon Drift Detector, calibrated with

104 standards containing multiple elements, was used to measure the X-ray fluorescence.

A larger map of the sample in question was created using the CLS-administered beamline

$10620 \mathrm{ID}$ at the Advanced Photon Source (APS), Argonne National Laboratory (Heald, et al., 2007)

107 using a liquid-nitrogen-cooled silicon (111) double-crystal monochromator set to an incident X-

108 ray energy of $16.5 \mathrm{keV}$. The APS was operating in top-up mode with $102 \mathrm{~mA}$ of current in the

109 ring. The incident flux was approximately $2 \times 10^{11}$ photons per second within the $5 \times 5 \mu \mathrm{m}^{2}$

110 micro-focus beam spot obtained from the KB-mirrors.

111 Open source (ImageJ: http://rsbweb.nih.gov/ij/) and custom software were used to

112 convert the raw data into images. Since a correlation between biological structures and the

113 spatial distributions of trace elements is indicative of biogenic uptake, the XFI data were

114 compared with the bone histology.

115

\subsection{Synchrotron X-ray Absorption Spectroscopy}

117 XAS measurements were conducted at the Stanford Synchrotron Radiation Lightsource

118 (SSRL) with the SPEAR storage ring containing $450 \mathrm{~mA}$ at $3.0 \mathrm{GeV}$. Hg L LII-edge data were

119 collected on the structural molecular biology XAS beamline 7-3, employing a Si(220) double-

120 crystal monochromator and an upstream rhodium-coated collimating mirror was used to reject

121 photons above $15 \mathrm{keV}$. Beam size was approximately $1 \mathrm{~mm}$ by $3 \mathrm{~mm}(\mathrm{VxH})$. X-ray absorption

122 of the bone sample was collected in fluorescence mode using the $\mathrm{Hg} \operatorname{L} \alpha_{12} \mathrm{X}$-ray fluorescence

123 excitation spectrum with a Canberra (Meriden CT, USA) high-purity germanium array detector 
124 (Cramer, et al., 1988), with incident and transmitted X-ray intensities being measured using

125 nitrogen filled gas ionization detectors with a sweeping voltage of $1800 \mathrm{~V}$. The larger beam size

126 was chosen to reduce flux density on the sample and lessen the likelihood of beam damage.

127 Multiple sweeps of the spectra were recorded to improve the signal to noise ratio but to also

128 ensure that photoreduction was not taking place. During data acquisition all samples were

129 maintained at 10K using an Oxford Instruments (Abingdon, Oxfordshire, UK) CF1204 liquid

130 helium flow cryostat.

131 In addition to the bone sample, spectra of standard $\mathrm{Hg}$ containing species were collected

132 for comparison and for use in data analysis (George, et al., 2009). These included $\mathrm{Hg}$ in the

133 elemental state as well as a wide range of organometallic and inorganic $\mathrm{Hg}$ species. XAS data

134 were processed using standard techniques (George, et al., 2008) using the EXAFSPAK suite of

135 software (http://ssrl.slac.stanford.edu/exafspak.html). The near-edge portion of the $\mathrm{Hg}_{\mathrm{III}}$ XAS

136 was used to provide speciation information on the $\mathrm{Hg}$ present in the bone.

\section{3. Results}

In the XFI study, a portion of the scan indicated higher levels of $\mathrm{Hg}$ in the bone sample

140 and the pattern was clearly distinct from surrounding structures (Fig. 1). The spatial localization

141 of the $\mathrm{Hg}$ corresponds with compact bone features (osteons) that are present as a result of bone

142 remodelling. Interestingly, the $\mathrm{Hg}$ is constrained within a small number of osteons.

143 A second sample from the same bone was used to determine the species of $\mathrm{Hg}$ through

144 the use of near-edge analysis. The chemical sensitivity of the $\mathrm{Hg}_{\mathrm{III}}$ near-edge spectra are much

145 less than those of K-edge spectra in the same energy range (e.g. As and Se). Because of this,

146 quite subtle variations in the spectra must be used to obtain speciation information, and as 
147 previously discussed (George, et al., 2008) spectra must have good signal to noise for a valid 148 analysis. In general, and as expected (George, et al., 2008, Korbas, et al., 2010), near-edge

149 spectra from similar structural sites resemble each other. For example, spectra from two-

150 coordinate linear oxygen-coordinated species (such as $\mathrm{Hg}_{3}\left(\mathrm{PO}_{4}\right)_{2}$ ) (Aurivillius and Nilsson,

151 1975) resemble one another, with a distinctive low-energy peak at $12285.8 \mathrm{eV}$, and are distinct

152 from two-coordinate sulfur bound species such as $\alpha-\mathrm{HgS}$ and these in turn from three and four

153 coordinate sulfur bound species. We note that some species such as $\mathrm{HgCl}_{2}$ do show a peak in

154 their $\mathrm{Hg} \mathrm{L}_{\mathrm{III}}$ near-edge spectra, but that this is at a higher energy around $12286.7 \mathrm{eV}$. Automatic

155 software (the EXAFSPAK program MATCHIT) was used to compare the experimental spectrum

156 with spectra from a library of 41 standards of $\mathrm{Hg} \mathrm{L}_{\mathrm{III}}$ near-edge spectra. Figure 2 shows a

157 comparison of the bone spectrum with those of a small number of selected standard compounds.

158 The MATCHIT program uses non-linear optimization of a polynomial background function and

159 linear scaling to find the closest match of experimental data from our library of 41 standard

160 compound spectra. For our bone samples, the closest match was found to be the beta form of

161 inorganic mercuric sulfide $(\beta-\mathrm{HgS})$ which has four-coordinate $\mathrm{Hg}(\mathrm{II})$ with sulfides. The next

162 nearest matches were all four-coordinate sulfur-bound species, and when two components were

163 allowed the best fit was found with essentially $100 \% \beta-\mathrm{HgS}$, with minor components being

164 incorporated below the threshold of detection which we estimate as about 4\%. Very similar

165 results were obtained with larger scale multi-component fits using the EXAFSPAK program

166 DATFIT. Even empirically, the spectrum of the bone appears quite distinct from that of

$167 \mathrm{Hg}_{3}\left(\mathrm{PO}_{4}\right)_{2}$ and lacks the characteristic low-energy peak at $\sim 12285.8 \mathrm{eV}$. The spectrum from the

168 bone sample is a close match to the spectrum of the $\beta-\mathrm{HgS}$, mineralogically known as

169 metacinnabar, indicating that the structure is four-coordinate with sulfur, and strongly suggesting 
170 the substantial presence of this compound in the sample. The close correspondence between the

171 bone spectrum and $\beta-\mathrm{HgS}$ is evident upon examination of Fig. 2.

\section{4. Discussion and Conclusions}

This study began after a standard ICP-MS analysis of bone samples from 17 individuals

175 recovered during salvage operations on the island of Antigua in the West Indies identified that

176 one bone sample contained an elevated level of $\mathrm{Hg}$. Our initial goal was to discern whether the

$177 \mathrm{Hg}$ was present due to biogenic uptake or as a result of post-mortem contamination. The soil at

178 the site was slightly alkaline and consisted of a hard mix of volcanic ash and gravel deposits. The

179 burial in question was the last in a row of 5 graves, $120 \mathrm{~cm}$ below the surface and similar to the

180 surrounding burials. The well-preserved remains resided within a six-sided wooden coffin with

181 ferrous metal nails. Associated artifacts were limited to eight bone buttons alongside the lumbar

182 and lower thoracic vertebrae. Bone buttons were common in the burials at the site and not a

183 likely source of $\mathrm{Hg}$ since this is the only skeleton in which the element was found at anything but 184 negligible levels.

185 For many centuries, the use of $\mathrm{Hg}$ was in fact controversial due to the limited knowledge 186 surrounding the impact of the element on healthy tissue. Abramowitz (1934) commented that 187 research in the $19^{\text {th }}$ century revealed $\mathrm{Hg}$ had no effect on the bone of humans or animals. In the 188 recent past, with technological advances, there have been new opportunities to identify metals 189 associated with bone (Lindh, et al., 1980).

190 A biogenic source of $\mathrm{Hg}$ associated with archaeological bone has been noted in previous 191 studies, including research by Yamada and colleagues (1997) who analyzed a number of burials 192 from the $3^{\text {rd }}$ to $6^{\text {th }}$ century in Japan when inorganic mercuric oxide was used in red cosmetics. 
193 The authors used the method of Inductively Coupled Plasma Atomic Emission Spectroscopy and

194 while their results suggested a connection between the presence of $\mathrm{Hg}$ and the use of red

195 cosmetics, they also commented that environmental contamination may have occurred.

196 A study by Rasmussen and colleagues (2008) revealed through atomic absorption the

197 presence of $\mathrm{Hg}$ in Danish medieval bones associated with individuals who likely had leprosy and

198 syphilis due to the apparent bone lesions. They noted that $\mathrm{Hg}$-containing medicine was used in

199 the majority of leprosy cases and almost half of syphilis cases during that time period

200 (Rasmussen, et al., 2008). As a way of identifying possible environmental contamination, the

201 authors tested the soil at regular intervals both vertically and horizontally away from where the

202 remains were excavated. They also noted that while they were able to achieve results indicating

203 various levels of $\mathrm{Hg}$ in the bones, the levels were too low for "any feasible mapping technique to

204 reveal even the location of Hg."

205 XFI, a technique that can localize specific chemical elements by monitoring their

206 characteristic X-ray fluorescence, has been used to study $\mathrm{Hg}$ in a variety of systems including

207 modern bones of skua and penguin, which are seabirds from the Antarctic (Zhouqing, et al.,

208 2005). This seabird study found that the $\mathrm{Hg}$ levels were higher in the periosteal and endosteal

209 surfaces. It is intriguing to use this same imaging technique on archaeological bone because of

210 the advantages of using synchrotron light that are not found in conventional techniques such as

211 faster scan speeds, higher spatial resolution and sensitivity to low trace element concentrations.

$212 \mathrm{Hg}$ can be isolated in the natural environment in areas with volcanic soil (Martin, et al.,

213 2012). The most common ore of environmental $\mathrm{Hg}$ is inorganic alpha mercuric sulfide

214 (cinnabar), but mercuric sulfide can also exist in the beta mercuric sulfide form (Barnett, et al.,

215 1997). Under normal environmental conditions, both forms are stable and highly insoluble in 
water (Dickson and Tunell, 1959). Recent work by Avila and colleagues suggests that cinnabar

217 does not interact with hydroxyapatite associated with post mortem remains (Avila, et al., 2014).

In this study, the data that were acquired from the XFI scan revealed the presence of $\mathrm{Hg}$

219 in some of the osteons but not in all of the osteons within the field of view. This evidence rules

220 out environmental contamination and is consistent with the biogenic uptake of $\mathrm{Hg}$ though it is

221 currently not possible to determine a time sequence.

222

223

224

225

226

227

228

229

230

231

232

233

234

235

236

237

238

239
The question how long mercury remains in the system, is one of practical importance. The antimercurialists speak in support of their favourite views, of its remaining many years in it; but there is no proof of this.

(MacPherson, 1874)

The level of $\mathrm{Hg}$ toxicity varies dramatically with the chemical form in which it is presented. The speciation of the $\mathrm{Hg}$ in the bone sample identified a form of inorganic $\mathrm{Hg} \beta-\mathrm{HgS}$, which can form in vivo and is known to accumulate in the kidneys; high levels will result in the termination of kidney function (Clarkson and Magos, 2006). In colonial times, the toxicity of $\mathrm{Hg}$ was acknowledged. One historical incident in 1810 involved the Royal ship H.M.S. Triumph while in harbour at Cadiz, Spain. The ship received approximately 130 tons of quicksilver (elemental Hg) from a damaged Spanish ship (Earles, 1964). Dr. William Burnett documented the accidental contamination of the Triumph with $\mathrm{Hg}$ (Burnett, 1823, Doherty, 2004). He commented that many of the crew were affected with ptyalism (excessive salivation), and some individuals suffered from partial paralysis and ulcerations of the mouth. It has been suggested that due to the mouth ulcerations, there is a greater potential for periodontitis, and when this condition is severe, the alveolar bone is impacted (Coventry, et al., 2000). It is interesting to speculate that since the individual in this current study had porous alveolar sockets, this individual may have been poisoned with $\mathrm{Hg}$. 
Improvements in synchrotron technology and the dissemination of its applicability have

241 resulted in not only modern bone studies (Pemmer, et al., 2013) but also in studies of relevance

242 to bioarchaeology and paleopathology (Bertrand, et al., 2012). In this study, the technique of

243 XFI provided evidence supporting the interpretation that the $\mathrm{Hg}$ was present due to biogenic

244 uptake with the additional structural information gained through XAS revealing that it was an

245 inorganic form of $\mathrm{Hg}$.

\section{Acknowledgements}

248 We would like to thank Renfei Feng and Robert Gordon, Beamline Scientists, for their valuable

249 knowledge and expertise. Part of the research described in this paper was performed at the

250 Canadian Light Source, which is supported by the Natural Sciences and Engineering Research

251 Council of Canada, the National Research Council Canada, the Canadian Institutes of Health

252 Research, the Province of Saskatchewan, Western Economic Diversification Canada, and the

253 University of Saskatchewan. Research was also carried out at the PNC/XSD facilities at the

254 Advanced Photon Source, and this research is supported by the US Department of Energy - Basic

255 Energy Sciences, a Major Resources Support grant from NSERC, the University of Washington,

256 the Canadian Light Source and the Advanced Photon Source. Use of the Advanced Photon

257 Source, an Office of Science User Facility operated for the U.S. Department of Energy (DOE)

258 Office of Science by Argonne National Laboratory, was supported by the U.S. DOE under

259 Contract No. DE-AC02-06CH11357. Additionally, research was carried out at the Stanford

260 Synchrotron Radiation Lightsource, a Directorate of SLAC National Accelerator Laboratory and

261 an Office of Science User Facility operated for the U.S. Department of Energy Office of Science

262 by Stanford University. The SSRL Structural Molecular Biology Program is supported by the 
DOE Office of Biological and Environmental Research and by the National Institutes of Health,

264 National Institute of General Medical Sciences (including P41GM103393) and the National

265 Center for Research Resources (P41RR001209). The contents of this publication are solely the

266 responsibility of the authors and do not necessarily represent the official views of NIGMS,

267 NCRR or NIH.

This research was supported by a Social Sciences and Humanities Research Council (ŜSHRC)

271 from Canada Research Chairs and research in the G.N.G. / I.J.P. laboratories is supported by

NSERC (Canada), SHRF and CIHR.

\section{References}

275

276

277

278

279

280

281
Aufderheide, A.C., Rodriguez-Martin, C., 1998. The Cambridge Encyclopedia of Human Paleopathology, Cambridge University Press, Cambridge. Abramowitz, E.W., 1934. Historical Points of Interest on the Mode of Action and Ill Effects of Mercury, Bulletin of the New York Academy of Medicine 10, 695-705. Yamada, M.-O., Tohno, S., Tohno, Y., Minami, T., Ichii, M., Okazaki, Y., 1995. Accumulation of mercury in excavated bones of two natives in Japan, Science of The Total Environment 162, 253-256.

Yamada, M., Minami, T., Yamada, G., Tohno, Y., Tohno, S., Ikeda, Y., Tashiro, T., Kohno, Y., Kawakami, K., 1997. Different element ratios of red cosmetics excavated from ancient burials of Japan, The Science of the Total Environment 199, 293-298.

Lopes, C., Powell, M.L., Santos, A.L., 2010. Syphilis and cirrhosis: a lethal combination in a XIX century individual identified from the Medical Schools Collection at the University of Coimbra (Portugal), Memórias do Instituto Oswaldo Cruz 105, 1050-1053.

Tucker, F., 2007. Kill or cure? The osteological evidence of the mercury treatment of syphilis in 17th- to 19th-century London, London Archaeologist 11, 220-224.

Kepa, M., Kozlowski, T., Szostek, K., Drozd, A., Walas, S., Mrowiec, H., Stepanczak, B., Glab, H., Grupa, M., 2012. Analysis of mercury levels in historical bone material from syphilitic subjects - pilot studies (short report, Anthropologischer Anzeiger 69, 367-377.

Swanston, T., Varney, T., Coulthard, I., Feng, R., Bewer, B., Murphy, R., Hennig, C., Cooper, D., 2012. Element localization in archaeological bone using synchrotron radiation X-ray fluorescence: identification of biogenic uptake, Journal of Archaeological Science 39, 24092413. 
Guzzi, G., La Porta, C.A.M., 2008. Molecular mechanisms triggered by mercury, Toxicology

298 244, 1-12.

299 Toribara, T.Y., Jackson, D.A., 1982. Nondestructive X-ray Fluorescence Spectrometry for

300 Determination of Trace Elements along a Single Strand of Hair, Analytical Chemistry 54, 1844-

3011849.

302 Sartin, J.S., Perry, H.O., 1995. From mercury to malaria to penicillin: The history of the treatment of syphilis at the Mayo Clinic-1916-1955, Journal of the American Academy of Dermatology 32, 255-261.

Musgrave, A., 1827. Observations on the Unmixed Effects of Mercury on the System, with a few Practical Remarks on some of the most important Tropical Diseases, The Edinburgh Medical and Surgical Journal: Exhibiting a Concise View of the Latest and Most Important Discoveries in Medicine Surgery, and Pharmacy 28, 36-61.

Jenner, G.A., Longerich, H.P., Jackson, S.E., Fryer, B.J., 1990. ICP-MS - A powerful tool for high-precision trace-element analysis in Earth sciences: Evidence from analysis of selected U.S.G.S. reference samples, Chemical Geology 83, 133-148.

Stefanova, V., Kmetov, V., Canals, A., 2003. Application of internal standardization in ICPQMS through discrete sample introduction methodologies, Journal of Analytical Atomic Spectrometry 18, 1171-1174.

Feng, R., Gerson, A., Ice, G., Reininger, R., Yates, B., McIntyre, S., 2007. VESPERS: A Beamline for Combined XRF and XRF Measurements, in: Choi, J.-Y., Rah, S. (Eds.), Synchrotron Radiation Instrumentation: Ninth International Conference, pp. 872-874. Heald, S.M., Cross, J.O., Brewe, D.L., Gordon, R.A., 2007. The PNC/XOR X-ray microprobe station at APS sector 20, Nuclear Instruments and Methods in Physics Research Section A: Accelerators, Spectrometers, Detectors and Associated Equipment 582, 215-217. Cramer, S.P., Tench, O., Yocum, M., George, G.N., 1988. A 13-element Ge detector for fluorescence EXAFS, Nuclear Instruments and Methods in Physics Research Section A: Accelerators, Spectrometers, Detectors and Associated Equipment 266, 586-591. George, G.N., Singh, S.P., Hoover, J., Pickering, I.J., 2009. The Chemical Forms of Mercury in Aged and Fresh Dental Amalgam Surfaces, Chemical Research in Toxicology 22, 1761-1764. George, G.N., Singh, S.P., Prince, R.C., Pickering, I.J., 2008. Chemical Forms of Mercury and Selenium in Fish Following Digestion with Simulated Gastric Fluid, Chemical Research in Toxicology 21, 2106-2110.

Korbas, M., O’Donoghue, J.L., Watson, G.E., Pickering, I.J., Singh, S.P., Myers, G.J., Clarkson, T.W., George, G.N., 2010. The Chemical Nature of Mercury in Human Brain Following Poisoning or Environmental Exposure, ACS Chemical Neuroscience 1, 810-818. Aurivillius, L., Nilsson, B.A., 1975. The crystal structure of mercury(II)phosphate, Hg3(PO4)2., Zeitschrift für Kristallographie 141, 1-10.

Lindh, U., Brune, D., Nordberg, G., Wester, P.-O., 1980. Levels of antimony, arsenic, cadmium, copper, lead, mercury, selenium, silver, tin and zinc in bone tissue of industrially exposed workers, Science of The Total Environment 16, 109-116.

Rasmussen, K.L., Boldsen, J.L., Kristensen, H.K., Skytte, L., Hansen, K.L., Mølholm, L., Grootes, P.M., Nadeau, M.-J., Flöche Eriksen, K.M., 2008. Mercury levels in Danish Medieval human bones, Journal of Archaeological Science 35, 2295-2306. Zhouqing, X., Bangbo, C., Liguang, S., Yuying, H., Wei, H., 2005. Preliminary investigation of mercury in bone tissues of skua and penguin in Antarctica using AFS and Synchrotron Radiation X-ray Fluorescence, Chinese Journal of Polar Science 16, 33-40. 
Martin, R.S., Witt, M.L.I., Sawyer, G.M., Thomas, H.E., Watt, S.F.L., Bagnato, E., Calabrese, S., Aiuppa, A., Delmelle, P., Pyle, D.M., Mather, T.A., 2012. Bioindication of volcanic mercury (Hg) deposition around Mt. Etna (Sicily), Chemical Geology 310-311, 12-22. Barnett, M.O., Harris, L.A., Turner, R.R., Stevenson, R.J., Henson, T.J., Melton, R.C., Hoffman, D.P., 1997. Formation of Mercuric Sulfide in Soil, Environmental Science \& Technology 31, 3037-3043.

Dickson, F.W., Tunell, G., 1959. The Stability Relations of Cinnabar and Metacinnabar, The American Mineralogist 44, 471-487.

Avila, A., Mansilla, J., Bosch, P., Pijoan, C., 2014. Cinnabar in Mesoamerica: poisoning or mortuary ritual?, Journal of Archaeological Science 49, 48-56.

MacPherson, J., 1874. Reumont on Metallic Poisoning and Its Treatment by Mineral Waters, in: Hart, E.A. (Ed.), The London Medical Record, Smith, Elder \& Co., London, pp. 509-511.

Clarkson, T.W., Magos, L., 2006. The Toxicology of Mercury and Its Chemical Compounds, Critical Reviews in Toxicology 36, 609-662.

Earles, M.P., 1964. A case of Mass Poisoning with Mercury Vapour on Board H.M.S. "Triumph" at Cadiz, 1810, Medical history 8, 281.

Burnett, W., 1823. An Account of the Effect of Mercurial Vapours on the Crew of His Majesty's Ship Triumph, in the Year 1810, Philosophical Transactions of the Royal Society of London 113, 402-408.

Doherty, M.J., 2004. The quicksilver prize: Mercury vapor poisoning aboard HMS Triumph and HMS Phipps, Neurology 62, 963-966.

Coventry, J., Griffiths, G., Scully, C., Tonetti, M., 2000. ABC Of Oral Health: Periodontal Disease, BMJ: British Medical Journal 321, 36-39.

Pemmer, B., Roschger, A., Wastl, A., Hofstaetter, J.G., Wobrauschek, P., Simon, R., Thaler, H.W., Roschger, P., Klaushofer, K., Streli, C., 2013. Spatial distribution of the trace elements zinc, strontium and lead in human bone tissue, Bone 57, 184-193.

Bertrand, L., Cotte, M., Stampanoni, M., Thoury, M., Marone, F., Schöder, S., 2012.

Development and trends in synchrotron studies of ancient and historical materials, Physics Reports 519, 51-96.

\section{Fig. 1. XFI Spatial Map}

375 Region of interest with the corresponding XFI spatial map (scale bar $=1 \mathrm{~mm}$ ): (A) bone

376 histology observed through light microscopy; and (B) a composite of the mercury XFI map (data

377 collected at the APS) at 40\% opacity with the histological image. The color gradient (value range

378 from 0.001 to 0.078 ) indicates the normalized XFI intensity but does not reflect the true

379 concentration. 
381 Fig. 2. Speciation using XAS

382 Comparison of $\mathrm{Hg} \mathrm{L}_{\mathrm{III}} \mathrm{X}$-ray absorption near-edge spectra of bone and selected standards. The

383 very close correspondence of the $\beta-\mathrm{HgS}$ standard and bone sample spectra indicates that the

384 majority of $\mathrm{Hg}$ present in the bone is present as $\beta-\mathrm{HgS}$.

385 


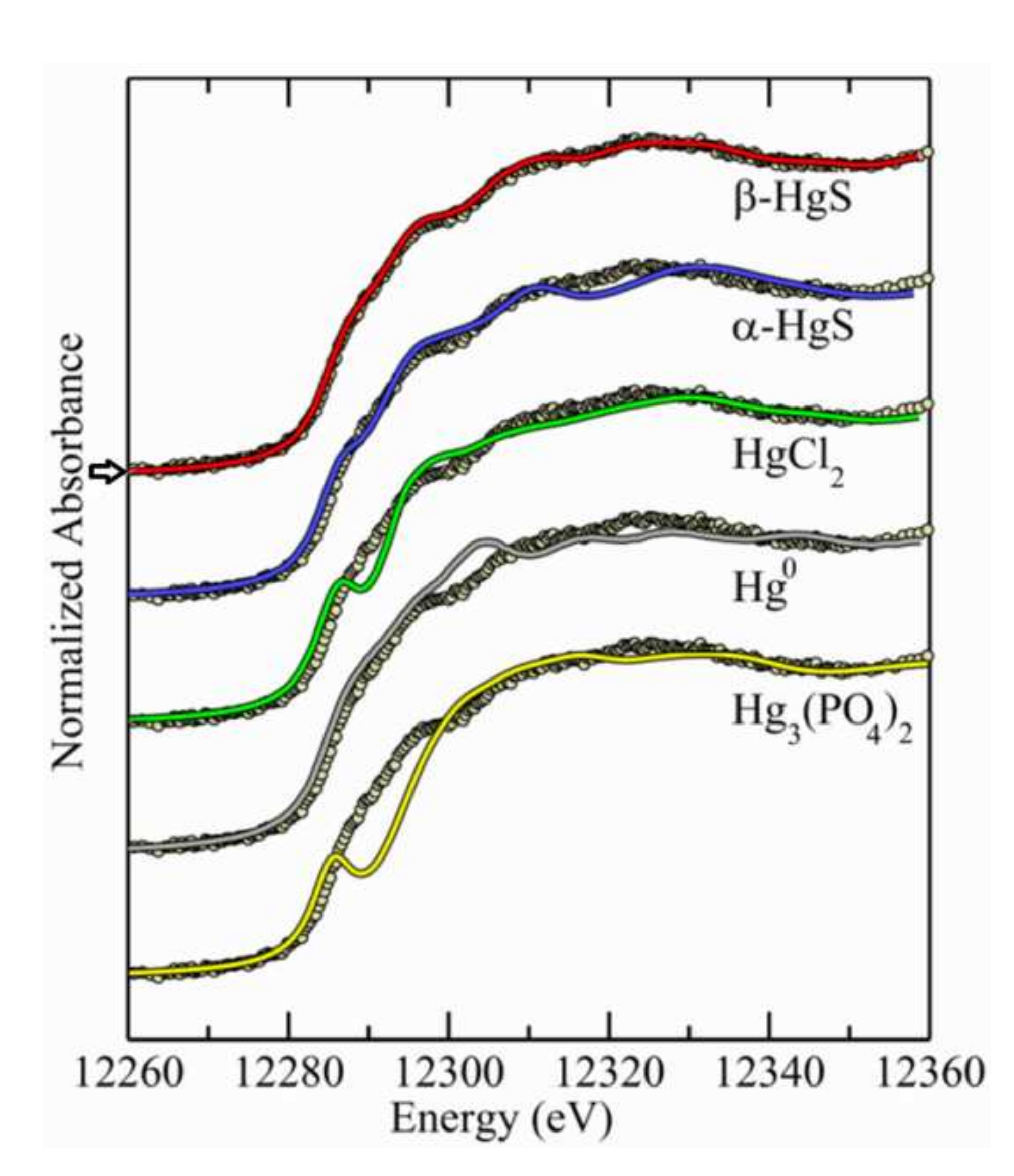

Figure 2

2

\section{Figure}

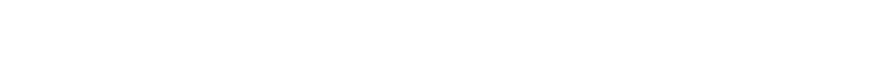

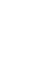

列
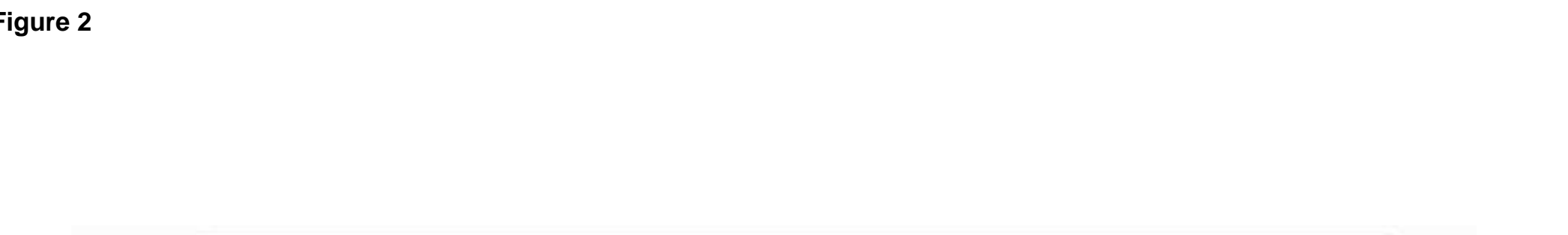